\title{
Kesetaraan Hasil Skrining Risiko Penyimpangan Perkembangan Menurut Gara Kuesioner Praskrining Perkembangan [KPSP] dan Denver II pada Anak Usia 12-14 Bulan dengan Berat Lahir Rendah
}

Fiva A Kadi, Herry Garna, Eddy Fadlyana

Bagian Ilmu Kesehatan Anak Fakultas Kedokteran Universitas Padjadjaran Bandung

\begin{abstract}
Latar belakang. Penilaian perkembangan pada anak penting dilakukan, terutama sampai usia 1 tahun untuk deteksi dini, agar bila ditemukan kecurigaan penyimpangan dapat dilakukan stimulasi dan intervensi dini sebelum terjadi kelainan. Depkes RI mengeluarkan revisi buku deteksi dini tumbuh kembang untuk identifikasi dini perkembangan di tingkat kecamatan berupa kuesioner praskrining perkembangan (KPSP) yang dapat dilakukan oleh tenaga kesehatan ataupun nonkesehatan terlatih.

Tujuan. Penelitian ini membandingkan kesetaraan hasil antara KPSP dan Denver II dalam mendeteksi kecurigaan penyimpangan perkembangan.

Metode. Penelitian dilakukan dengan metode evaluatif komparatif dan rancangan cross sectional, pada anak usia 12-14 bulan dengan berat lahir rendah di puskesmas Garuda Bandung pada bulan Februari sampai Maret 2008. Dengan menggunakan metode KPSP skrining dilakukan oleh kader kesehatan terlatih kemudian dibandingkan dengan Denver II oleh dokter, dan dinilai kesetaraan dari dua hasil pemeriksaan tersebut menggunakan perhitungan coefficient of agreement Kappa.

Hasil. Delapan puluh lima subjek penelitian diperiksa status perkembangan oleh 10 orang kader kesehatan (dipilih random dan lolos uji inter dan intra-observer) kemudian oleh 2 dokter. Dari KPSP didapatkan sebanyak 82,4\% normal dan 17,6\% curiga terganggu, menurut Denver II didapatkan sebanyak 77,6\% normal dan 22,4\% curiga terganggu. Nilai sensitifitas dan spesifisitas untuk KPSP dalam penelitian ini masing-masing adalah $95 \%$ dan 63\%, dengan nilai Kappa 0,552 dan $p<0,0001$.

Kesimpulan. Pemeriksaan KPSP setara moderate dengan Denver II dan dapat menjadi alat deteksi dini di tingkat Posyandu. Perlu dilakukan penelitian lebih lanjut pada usia dan tempat yang lebih bervariasi serta dengan jumlah kader yang lebih besar. (Sari Pediatri 2008;10(1):29-33).
\end{abstract}

Kata kunci: KPSP, Denver II, risiko penyimpangan perkembangan

Alamat Korespondensi:

Eddy Fadlyana, dr., Sp.A Bagian/SMF Ilmu Kesehatan Anak FKUP/

RSUP dr. Hasan Sadikin

Jl. Pasteur No. 38 Telp./Fax. 2034426-203595 Bandung 40161

Sari Pediatri, Vol. 10, No. 1, Juni 2008 
A nak merupakan generasi penerus suatu bangsa, dengan demikian dibutuhkan anak dengan kualitas yang baik agar tercapai masa depan bangsa yang baik. ${ }^{1}$ Untuk mendapatkan kualitas anak yang baik harus dipastikan bahwa tumbuh dan kembangnya juga baik. ${ }^{1,2}$ Perkembangan seorang anak spesifik dan berbeda. Perkembangan anak merupakan maturasi organ tubuh terutama sistem saraf pusat (SSP). Tahapan yang terpenting pada perkembangan anak adalah pada 3 tahun pertama, karena perkembangan berlangsung dengan pesat dan menentukan masa depan anak kelak (teori plastisitas). ${ }^{3,4}$

Skrining perkembangan untuk deteksi dini pada setiap anak penting dilakukan, terutama pada anak sampai usia 1 tahun agar bila ditemukan kecurigaan penyimpangan perkembangan dapat segera dilakukan intervensi dini sebelum terjadi kelainan. Dari beberapa sumber kepustakaan didapatkan bahwa intervensi pada anak dengan kecurigaan penyimpangan perkembangan sebaiknya dilakukan sebelum usia 3 tahun. ${ }^{5}$ Ada beberapa jenis alat/cara untuk melakukan penilaian/skrining perkembangan pada seorang anak, satu di antaranya yang sudah terbukti menunjukkan sensitivitas dan spesifisitas baik adalah menggunakan Denver II. ${ }^{6}$ Denver II merupakan salah satu skrining yang telah banyak digunakan oleh profesi kesehatan di dunia termasuk Indonesia. ${ }^{6}$

Tidak pada semua anak dapat dilakukan skrining perkembangan karena yang biasa melakukan adalah dokter anak, dan memerlukan biaya cukup mahal, sementara Departemen Kesehatan RI mengharapkan pada tahun $2010,80 \%$ anak balita sudah dilakukan skrining perkembangan agar dapat dilakukan intervensi dini terhadap anak yang dicurigai mengalami gangguan perkembangan. ${ }^{7}$ Depkes RI pada tahun 2005 mengeluarkan revisi buku deteksi dini tumbuh kembang yang bertujuan identifikasi dini perkembangan anak di tingkat terbawah, yaitu tingkat kecamatan, berupa kuesioner praskrining perkembangan (KPSP). ${ }^{7}$ Metode KPSP ini bertujuan untuk mengetahui perkembangan seorang anak apakah sesuai dengan usianya ataukah ditemukan kecurigaan penyimpangan, KPSP dapat dilakukan oleh tenaga kesehatan ataupun tenaga non kesehatan yang terlatih. ${ }^{7}$

Sejak tahun 1985 dikeluarkan instruksi bersama antara Menteri Dalam Negeri, Menteri Kesehatan, dan Kepala Badan Koordinator Keluarga Berencana Nasional (BKKBN) untuk kerja sama lintas sektoral dan lintas program, yang pelaksanaannya secara operasional dibentuklah pos pelayanan terpadu (posyandu).$^{8}$ Posyandu ini merupakan wadah titik temu antara pelayanan profesional dari petugas kesehatan dan peran serta masyarakat dalam menanggulangi masalah kesehatan masyarakat, yang operasionalnya dilakukan oleh masyarakat yang disebut sebagai kader kesehatan. Melalui kader kesehatan, pelayanan kesehatan yang selama ini dikerjakan oleh petugas kesehatan saja dapat dibantu oleh masyarakat. ${ }^{8}$

Berat lahir masih merupakan parameter outcome pembangunan bangsa terbaik. ${ }^{9}$ Angka kejadian bayi berat lahir rendah sebagai salah satu indikator status kesehatan dalam masyarakat erat kaitannya dengan kondisi sosioekonomi masyarakat seperti pendidikan, penghasilan, dan pola hidup. ${ }^{9}$ Menurut profil kesehatan Departemen Kesehatan Indonesia tahun 2004, insidens BBLR sekitar $14 \%$ dari kelahiran hidup..$^{10}$ Di RS Hasan Sadikin, insidensi BBLR pada tahun 2006 sekitar $22,7 \% .^{11}$

Bayi berat lahir rendah (BBLR) mempunyai risiko lebih tinggi untuk terjadinya penyimpangan perkembangan dibandingkan dengan populasi bayi umumnya. Risiko penyimpangan perkembangan pada BBLR sebanyak 2-5 kali lebih sering dibandingkan dengan bayi lahir dengan berat normal. ${ }^{12}$

\section{Metode}

Penelitian dilakukan dengan metode evaluatif komparatif terhadap anak usia 12-14 bulan dengan berat lahir 1.501-2.499 gram untuk menilai kesetaraan antara pemeriksaan uji tapis KPSP dan Denver II dalam menilai risiko penyimpangan perkembangan anak dengan rancangan cross sectional. ${ }^{13}$ Subjek diikutsertakan dalam penelitian jika orangtua menyetujui setelah mendapat penjelasan mengenai penelitian (informed consent). Penelitian dilaksanakan pada bulan Februari sampai Maret 2008 di Puskesmas Garuda Kota Bandung terhadap 85 subjek yang dapat mengikuti penelitian sampai akhir.

Data subjek berdasarkan data kelahiran di catatan medis Puskesmas Garuda Bandung dan RSHS subbagian Perinatologi yang pada saat penelitian sesuai dengan kriteria inklusi, yaitu berusia 12-14 bulan, sehat, mempunyai riwayat persalinan yang 
jelas, dan berdomisili di Bandung. Subjek tidak dapat ikut penelitian jika ditemukan kelainan perkembangan permanen seperti palsi serebral, sindrom down dan meningitis. Data bayi yang dicatat adalah nama bayi, alamat, tanggal lahir, nilai APGAR, riwayat persalinan, riwayat infeksi, kuning, dan distres napas. Orangtua subjek diberikan/dikirim surat tawaran untuk dilakukan penilaian perkembangan pada anaknya di Puskesmas Garuda atau diadakan kunjungan rumah.

Sebelum dilakukan penelitian, dilakukan kegiatan para penelitian satu minggu sebelumnya terhadap kader kesehatan yang akan melakukan pemeriksaan KPSP, berupa pemilihan 10 orang kader kesehatan secara random, pelatihan pemakaian KPSP pada kader kesehatan selama 2 hari, dan uji coba pemeriksaan oleh kader dengan menggunakan KPSP. Penelitian pendahuluan untuk mengetahui tingkat reliabilitas metode KPSP di antara kader kesehatan dan antara kader dengan dokter menggunakan coefficient of agreement Kappa. ${ }^{13,14}$

\section{Hasil}

Pada penelitian pendahuluan untuk menilai reliabilitas penggunaan KPSP oleh kader kesehatan dilakukan penelitian inter dan intraobserver pada kader tehadap kader kesehatan lainnya, juga antara hasil pemeriksaan KPSP oleh kader kesehatan dibandingkan dengan dokter. Dari kedua penelitian pendahuluan tersebut didapatkan nilai Kappa mempunyai tingkat reliabilitas yang amat baik antara pemeriksa dan secara statistik bermakna, didapatkan nilai Kappa 0,82 (kesetaraan almost perfect) pada pemeriksaan antar kader kesehatan dan Kappa 0,72 (kesetaraan substansial) antara kader kesehatan dan dokter, serta keduanya mempunyai nilai $p=0,0001$ (bermakna). ${ }^{13,14}$

Sepuluh orang kader yang terpilih adalah ibu rumah tangga yang sudah membantu kegiatan posyandu antara 3 sampai 15 tahun. Kader yang terpilih tersebut mempunyai usia dan latar belakang pendidikan yang bervariasi antara SD sampai SMA. Tabel 1 memperlihatkan karakteristik kader yag melakukan pemeriksaan KPSP. Tabel 2 memperlihatkan karakteristik 85 subjek penelitian penelitian, dan Tabel 3 memperlihatkan karakteristik ibu subjek.
Dari 10 kader terpilih didapatkan sebanyak 7 (70\%) orang yang sudah berpengalaman menjadi kader kesehatan lebih dari 10 tahun dengan usia ratarata 25-45 tahun (60\%). Dari Tabel 2 didapatkan $55,3 \%$ subjek laki-laki, 39 berusia 12 bulan (45,9\%), 26 berusia 13 bulan $(30,6 \%)$, dan 20 subjek berusia 14 bulan (23,5\%). Berat lahir dari 51 (60\%) subjek 2.001-2.499 gram dan 34 (40\%) mempunyai berat lahir 1.501-2000 gram.

Pendidikan ibu subjek sangat bervariatif, sebanyak 16 orang $(18,8 \%)$ lulusan sekolah dasar, $25(29,4 \%)$ orang lulusan SMP, $35(41,2 \%)$ orang lulusan SMA, dan masing-masing tiga (3,5\%) orang lulus Diploma-

Tabel 1. Karakteristik kader berdasarkan tingkat pendidikan, usia, dan lama menjadi kader

\begin{tabular}{lll}
\hline Karakteristik kader & $\mathrm{n}$ & $\%$ \\
\hline Pendidikan Kader & & \\
SD & 6 & 60 \\
SMP & 2 & 20 \\
SMA & 2 & 20 \\
Lama menjadi kader (tahun) & & \\
$\quad<5$ & 1 & 10 \\
$5-<10$ & 2 & 20 \\
$10-15$ & 7 & 70 \\
$>15$ & - & - \\
Usia (tahun) & & \\
$<25$ & 3 & 30 \\
$25-45$ & 6 & 60 \\
$>45$ & 1 & 10 \\
\hline
\end{tabular}

Tabel 2. Karakteristik subjek

\begin{tabular}{lll}
\hline \multicolumn{1}{c}{ Variabel } & $\mathrm{n}$ & $\%$ \\
\hline Jenis kelamin & & \\
$\quad$ Laki-laki & 38 & 44,7 \\
Perempuan & 47 & 55,3 \\
& & \\
Usia (bulan) & & \\
12 & 39 & 45,9 \\
13 & 26 & 30,6 \\
14 & 20 & 23,5 \\
& & \\
Berat lahir (gram) & & \\
$\quad>1500-2000$ & 34 & 40 \\
$\quad>2000-<2500$ & 51 & 60 \\
\hline
\end{tabular}


1 sampai Strata-1. Sebanyak 58 ibu subjek hanya memiliki satu orang anak $(68,2 \%)$, hanya tujuh ibu $(8,2 \%)$ yang memiliki anak lebih dari tiga orang. Sementara $11(12,9 \%)$ ibu dan sembilan $(10,6 \%)$ ibu memiliki masing-masing dua dan tiga anak. Dari 85 subjek penelitian, berat lahir terendah 1.510 gram dan berat lahir tertinggi 2.455 gram dengan median 2.100 gram. Usia kehamilan saat bayi dilahirkan berkisar antara 30 minggu sampai 36 minggu dengan median 33,2 minggu.

\section{Hasil pemeriksaan status perkembangan}

Pada 85 subjek penelitian dilakukan penilaian status perkembangan oleh 10 orang kader kesehatan yang berbeda dan dua orang dokter yang berbeda. Hasil pemeriksaan terhadap 85 subjek menurut KPSP terdapat sebanyak 70 anak $(82,4 \%)$ normal dan sebanyak 15 anak (17,6\%) curiga terganggu, sedangkan menurut pemeriksaan Denver II terdapat 66 (77,7\%) normal, dan $19(22,4 \%)$ curiga terganggu.

Tabel 3. Karakteristik ibu subjek penelitian

\begin{tabular}{lcc}
\hline \multicolumn{1}{c}{ Variabel } & $\mathrm{n}$ & $\%$ \\
\hline Pendidikan Ibu & & \\
SD & 16 & 18,8 \\
SMP & 25 & 29,4 \\
SMA & 35 & 41,2 \\
D1 & 3 & 3,5 \\
D3 & 3 & 3,5 \\
S1 & 3 & 3,5 \\
Jumlah Anak & & \\
1 & 58 & 68,2 \\
2 & 11 & 12,9 \\
3 & 9 & 10,6 \\
$>3$ & 7 & 8,2 \\
\hline
\end{tabular}

Tabel 5. Pemeriksaan skrining perkembangan

\begin{tabular}{|c|c|c|c|c|c|c|c|}
\hline & \multicolumn{4}{|c|}{ Denver II } & \multirow{2}{*}{\multicolumn{2}{|c|}{ Total }} \\
\hline & & \multicolumn{2}{|c|}{ Normal } & \multicolumn{2}{|c|}{ Curiga terganggu } & & \\
\hline & & $\mathrm{n}$ & $\%$ & $\mathrm{n}$ & $\%$ & $\mathrm{n}$ & $\%$ \\
\hline \multirow{3}{*}{ KPSP } & Normal & 63 & 74,1 & 7 & 8,3 & 70 & 82,4 \\
\hline & $\begin{array}{l}\text { Curiga } \\
\text { terganggu }\end{array}$ & 3 & 3,5 & 12 & 14,1 & 15 & 17,6 \\
\hline & Total & 66 & 77,6 & 19 & 22,4 & 85 & 100 \\
\hline
\end{tabular}

Tabel 5 memperlihatkan kesetaraan penilaian perkembangan dengan menggunakan KPSP yang dilakukan oleh kader kesehatan dibandingkan dengan Denver II yang dilakukan oleh dokter dengan menggunakan Coefficient of agreement Kappa. Dengan menggunakan SPSS didapatkan nilai Kappa sebesar 0,552 (setara moderate) dengan nilai $p<0,05$ (bermakna).

\section{Pembahasan}

Suatu alat skrining perkembangan yang baik, harus memenuhi beberapa kriteria, mudah dilakukan, murah, dapat diterima untuk masyarakat, akurat, sensitif, spesifik, serta dapat diulang oleh orang lain dengan tingkat reliabilitas yang baik. Nilai reliabilitas yang baik didapatkan setelah dilakukan uji antara masing-masing observer/pemeriksa dengan satu subjek, ataupun satu observer pada beberapa subjek (uji inter dan intraobserver). Didapatkan hasil dengan tingkat reliabilitas yang amat baik antara kader kesehatan dan dokter.

Berdasarkan hasil penilaian status perkembangan pada anak usia 12-14 bulan dengan berat lahir 1.501-2.499 gram di Puskesmas Garuda dengan menggunakan KPSP, $17,6 \%$ subjek didapatkan kecurigaan mengalami gangguan perkembangan, sedangkan dengan menggunakan Denver II didapatkan lebih banyak, 22,4\%. Temuan ini lebih besar dibandingkan dengan penelitian sebelumnya yang dilakukan oleh Dhamayanthi pada tahun 2003 dengan menggunakan KPSP dan Denver II, yaitu didapatkan curiga gangguan perkembangan 15\% menurut KPSP dan 12\% menurut Denver II. ${ }^{10} \mathrm{Hal}$ ini mungkin disebabkan karena pada penelitian sebelumnya subjek tidak mengikutsertakan anak dengan riwayat berat lahir rendah tetapi dilakukan pada bayi dengan berat lahir normal. Terdapat 5-15\% bayi dengan berat lahir 1.501-2.499 gram mempunyai kelainan perkembangan, ${ }^{22}$ yang dilakukan pada daerah padat, mempunyai sosial ekonomi kurang serta kepedulian kurang terhadap perkembangan anak.

Sensitivitas dan spesifitas yang diharapkan dari suatu alat skrining yang baik mempunyai nilai masing-masing sebesar $80 \%$. Penggunaan KPSP jika dibandingkan dengan Denver II mempunyai nilai sensitivitas $95 \%$ dan spesifisitas 63\%. Hal ini mungkin disebabkan karena metode KPSP merupakan suatu kuesioner tertutup yang jawabannya hanya ya dan tidak. Sementara itu ibu di Indonesia sering 
malu untuk mengakui bahwa anaknya tidak sepandai anak lain dengan usia sebaya sehingga jawaban yang dikeluarkan tidak sesuai dengan kenyataan, atau pemahaman terhadap pertanyaan yang diterima oleh ibu membingungkan. Uji statistik mengenai kesetaraan antara pemeriksaan status perkembangan KPSP dibandingkan dengan Denver II menggunakan Coefficient of agreement Kappa didapatkan nilai Kappa 0,552 (kecocokan moderate menurut Landis dan Koch, serta kecocokan baik menurut Fleiss) dengan nilai $p<0,05$ (bermakna). Dari kedua pemeriksaan tersebut jika dihitung akurasi pemeriksaan didapatkan $88,2 \%$, (nilai akurasi $>75 \%$ berarti baik). Penelitian dilakukan pada satu tempat dan pada satu titik usia, sehingga kurang mencerminkan kesetaraan pada usia lainnya dan jumlah kader yang diikutsertakan sebaiknya lebih banyak.

\section{Kesimpulan}

Kuesioner praskrining perkembangan (KPSP) pada anak usia 12-14 bulan dengan berat lahir rendah yang dilakukan oleh kader kesehatan merupakan uji deteksi risiko penyimpangan perkembangan yang setara dengan Denver II yang dilakukan oleh dokter. Pemeriksaan skrining perkembangan dengan menggunakan KPSP dapat dilakukan oleh kader kesehatan yang sudah dilatih dengan baik.

\section{Daftar Pustaka}

1. Soetjiningsih. Tumbuh kembang anak. Dalam: Ranuh IGN, penyunting. Tumbuh kembang anak. Jakarta: EGC; 1995. h. 1-32.

2. Moersintowati. Deteksi dini tumbuh kembang. Simposium penatalaksanaan mutakhir bidang ilmu kesehatan anak untuk mencapai tumbuh kembang optimal. Bandung: IDAI Jawa Barat; 2000.

3. Narendra M. Penilaian pertumbuhan dan perkembangan anak. Dalam: Narendra M, Sularyo, Soetjiningsih, penyunting. Tumbuh kembang anak dan remaja. Edisi ke-1. Jakarta: Sagung Seto; 2002. h. 95-7.

4. Tanuwidjaja S. Konsep tumbuh kembang anak. Dalam: Narendra M, Sularyo, Soetjiningsih, penyunting. Tumbuh kembang anak dan remaja. Edisi ke-1. Jakarta: Sagung Seto; 2002. h. 1-12.
5. Darmosubroto S. Instrumen pemantauan tumbuh kembang anak. Dalam: Pusponegoro HD, Taslim, penyunting. Deteksi dan intervensi dini penyimpangan tumbuh kembang anak dalam upaya optimalisasi kualitas sumber daya manusia. Pendidikan Kedokteran Berkelanjutan Ilmu Kesehatan Anak. Jakarta: FKUI; 1996. h. 125-31.

6. Frankerburg WK, Doddss JB. The Denver II: a major revision and restandardization of the Denver developmental screening test Denver II technical manual. Pediatrics. 1992;89:91-7.

7. Departemen Kesehatan Republik Indonesia. Kuesioner praskrining perkembangan. Dalam: Rusmil K, Hernawati I, Fadlyana E, Dhamayanti M, Dashriati, Herniyati $S$, dkk. Pedoman pelaksanaan stimulasi, deteksi dini dan intervensi dini tumbuh kembang anak di tingkat pelayanan kesehatan dasar. Jakarta: Depkes RI; 2005. h.71-86.

8. Zulkifli. Posyandu dan kader kesehatan. Fakultas Kesehatan Masyarakat. Universitas Sumetera. Diunduh tgl 12 April 2008. Didapat dari: http://library.usu.ac.id/download/fkm/fkm-zulkifli1.pdf

9. Bennet FC. Developmental outcome. Dalam: Avery GB, Fletcher M, MacDonald MG, penyunting. Neonatology: pathophysioogy and management of the newborn. Edisi ke-5. Philadelphia: JB Lippincott; 1999. h. 1479-97.

10. Departemen Kesehatan Republik Indonesia. Profil kesehatan Indonesia. Jakarta: Pusat Data Kesehatan; 2004.

11. Laporan Tahunan Perinatologi RS. Dr. Hasan Sadikin. Bandung: Bagian Ilmu Kesehatan Anak FK Unpad; 2007.

12. Gomella TL. Intrauterine growth retardation (small for gestational age infant). Dalam: Gomella TL, Cunningham D, Eyal FG, Zenk KE, penyunting. Neonatology: management, procedures, on-call problems, diseases and drugs. Edisi ke-5. New York: McGraw-Hill; 2004. h. 469-75.

13. Bishop YM, Fierberg SE. Discrete multivariate analysis. Dalam: Light RS, penyunting. Theory and practical statistic. London: MIT Press. Cambridge; 1975. h. 397-8.

14. Feinstein AR. Principal of medical statistic. New York: Langman and Hall; 2002. h. 235-56

15. Hall David, Hill Peter, Elliman David. The Child Surveillance Handbook. Oxford: Radcliffe Medical Press,2003. Diunduh tanggal 2 April 2008. Didapat dari: http://www.healthsci.utas.edu.au/medicine/teaching $/ \mathrm{kfp} / \mathrm{kfp} 3$ 